\title{
Comunicação corporativa: em rede e cada dia mais social
}

\section{Corporate communication: on the network and increasingly social}

\section{Comunicación corporativa: en red y cada día más social}

novação e resiliência são os mantras recorrentes de gestores,

comunicadores e todos os demais profissionais envolvidos na cena digital de nossa sociedade. Mantras a serem entendidos de um modo dirigido para os campos da comunicação organizacional e das relações públicas. Inovação, para além da mudança tecnológica, como um movimento de renovação, uma espécie de onda de frescor que agrega valor a produtos, serviços e processos de qualquer organização. E resiliência, como a capacidade de um sistema ou uma organização se antecipar e se adaptar a rupturas, eventos, lidar com as mudanças e reconstruir seus valores e estruturas a partir desses movimentos.

São posturas estratégicas essenciais e indispensáveis para todas as atividades que envolvam relacionamentos, sociabilidade, interações, transações, midiatizações, mediações. São pontos de reflexão e inflexão para qualquer atividade organizativa que atue no contexto contemporâneo onde predominam, entre muitas, as relações em rede (digitais ou físicas), a fluidez e mutabilidade dessas relações, as narrativas múltiplas e não controladas em torno de marcas e temas, as ambiências em redes digitais autônomas que abrigam todo tipo de diálogo e manifestação, e as possibilidades algorítmicas de identificação de usuário e direcionamento de conteúdos.

Tal contexto inspirou a definição do dossiê desta edição no 22 de Organicom, "Redes sociais: usos corporativos", mostrando aos leitores como essas abordagens de inovação e resiliência estão sendo discutidas por pesquisadores acadêmicos em artigos e entrevista, profissionais de mercado com seus depoimentos e a própria literatura 
resenhada; e também ampliando a discussão para o conteúdo dos artigos das seções Espaço Aberto e Pesquisa. Resultou daí numa edição robusta, possibilitando um amplo leque de abordagens de autores nacionais e internacionais.

Esse dossiê também nasceu cercado de desafios. 0 primeiro deles refere-se ao protagonismo da atividade comunicativa nas organizações, evidenciado proporcionalmente à intensidade da consolidação das tecnologias digitais de informação e comunicação (TICS) na sociedade contemporânea. Tal protagonismo propõe para as organizações um desafio constante, seja em termos de acompanhamento dos processos de inovação tecnológica, seja, principalmente, na sua capacidade de incorporação das inovações e transformação de seu ambiente, suas estratégias e sua cultura organizacionais diante da aceleração do mundo digital e da própria adaptabilidade e rápida absorção que a sociedade (os públicos) tem desse contínuo "admirável mundo novo", parafraseando Aldous Huxley.

A percepção coletiva de que vivemos numa sociedade envolvida pelo digital é constantemente evidenciada pela mídia, pelo comportamento dos grupos sociais influenciadores de opinião, por estímulos ao consumo e por sucessivas ondas de novidades e símbolos. Não obstante, sabemos que muitas organizações ainda permanecem cultural e estrategicamente fincadas em processos mais tradicionais, hierarquizados e unidirecionais no que se refere à comunicação, ao relacionamento e à estruturação de suas atividades. Nem todos andam no mesmo ritmo, e é aqui que se concentra uma maioria significativa de empresas. E é aqui, também, que estão os desafios.

Um segundo desafio é inerente às posturas de inovação e resiliência: a absorção da transformação de alguns conceitos anteriormente pétreos para o mundo da comunicação corporativa - o público assumindo o papel de uma audiência ativa e autônoma; a mensagem adquirindo o status de storytelling e de branded contentadequados às necessidades da audiência e não mais do produto ou da imagem de marca; e a rede como o locus hibridizado (on-line e off-line) e mutativo de atuação comunicativa.

Consequentemente, o terceiro desafio emerge do ritmo de inovação que as tecnologias digitais de informação e comunicação nos impõem. Hoje (e questionando a validade de nossa afirmação quando do lançamento desta edição) temos como carroschefes mobilidade, geolocalização e big data conduzindo processos, ambiências, apps, fanpages, estratégias e demais ações. Estaríamos nos despedindo das home-pages como cartões de visita da comunicação nas empresas?

0 quarto desafio põe em questão o próprio papel das relações públicas e da comunicação corporativa. Temos diante das organizações comunicantes uma massa de audiência tecnológica e discursivamente empoderada pelas ambiências com funções de mídia - a exemplo dos populares Facebook e Twitter -, abrigando uma multiplicidade de redes sociais de pessoas em torno de interesses, marcas, relacionamentos emocionais/sociais/comerciais. Tal cenário corrobora as afirmações de pesquisadores, consultores, agências de relações públicas - na sociedade contemporânea toda empresa é uma empresa de mídia. E, se assim concordamos, também deveríamos assumir que toda audiência é configurada em rede; e que toda comunicação de marca é destinada à audiência conectada em redes sociais.

Mais um desafio: nesse cenário é difícil preconizar um modelo fechado de comunicação corporativa e, muito menos, um modelo em separado para tal comunicação nas ambiências digitais. Se inovação e resiliência são assumidos como mantras, há também que assumirmos a flexibilidade com relação à adaptabilidade da estratégia e da ação de comunicação das organizações diante das mutações contínuas que vivenciamos.

Assim, pensar estratégias de comunicação na contemporaneidade digital inicia-se no conhecimento, na compreensão e na identificação do ecossistema midiático no qual a empresa se insere. Tal processo resulta na clareza de que a comunicação irá ocorrer em inter-relação contínua com todos os componentes do ecossistema, sejam estes posicionados interna ou externamente em relação ao ambiente organizacional. E, por fim, pensar estrategicamente a comunicação do ponto de vista 
da ecologia midiática implica um estado de mutação e adaptação contínuo das atividades comunicativas da organização em razão das flutuações naturais do próprio ecossistema - aquelas que ocorrem tipicamente na sociedade, na cultura, na tecnologia e no mercado.

A partir de mantras e desafios, o dossiê "Redes sociais: usos corporativos" tem como âncora a entrevista com o professor Derrick de Kerckhove, continuador dos estudos de Marshall McLuhan, que nos proporciona um diálogo instigante sobre como as relações corporativas no mundo do big data e sistemas de relacionamento digitais se transformam diante de uma nova ética de sociabilidade.

Um conjunto de textos traz a discussão sobre a transformação do campo e das estratégias de comunicação para as organizações por meio de Carolina Frazon Terra - "Relacionamentos nas mídias sociais (ou relações públicas digitais): estamos falando da midiatização das relações públicas?"; e de Bianca Marder Dreyer - "Estratégias de relações públicas para as organizações em tempos de mídias sociais digitais". A pesquisadora Else Lemos Inácio Pereira também contribui nesta mesma vertente com o artigo "Comunicação integrada, relações públicas e gestão da reputação em ambientes digitais: uma perspectiva crítica".

Os aspectos de narrativa, discursos organizacionais, personalização e branded content são apresentados no texto de Elizabeth Moraes Gonçalves e Vanda Souza Machado - "Discursos organizacionais: as relações de consumo no ambiente das redes sociais digitais"; e no de Beatriz Brandão Polivanov - "Personas no Facebook e consumo da afiliação: percepções sobre (des)encaixes entre selves on e off-line.

O delicado relacionamento das marcas com seus fãs e, também, inversamente, da celebridade e sua presença nas ambiências de mídias sociais são discutidas em pesquisas de campo retratadas no texto de Rejane de Oliveira Pozobon e Paula Purper Arruda - "A celebridade política Romário: análise das interações propostas no seu perfil oficial do Facebook", presente no Dossiê, e, na seção de Pesquisa, no trabalho apresentado por Adriana da Rosa Amaral e Augusto Rodrigues Parada - "Fãs organizacionais e o discurso mnêmico nas mídias sociais: observações a partir do estudo do Canal Viva".

0 dossiê traz, ainda, interessantes estudos de caso de posicionamento de presença de marca ou de organização nas ambiências sociais, com os artigos de Maximiliano Martin Vicentee Christiane Delmondes Versuti- "Rádio educativa e mídias sociais digitais: perspectivas e desafios da fanpage da Rádio Unesp FM"; João Figueira - "O Facebook como estratégia de superação da escassez de meios na comunicação institucional: o caso da Faculdade de Letras da Universidade de Coimbra"; Eva Márcia Arantes Ostrosky Ribeiro e Tiago Mainieri - "O uso das mídias sociais pelo governador do estado de Goiás: estratégia de marketing político ou comunicação pública?"; Jones Machado e Eugenia Maria Mariano da Rocha Barrichello - "Comunicação de crise em mídias sociais digitais: um estudo do Twitter, do Facebook e do blog corporativo da Petrobras"; e, na seção de Pesquisa, o texto de Felipe Chibás Ortiz e Melanie Cipolla- "Estratégias criativo-inovadoras de comunicação institucional de empresas em mídias sociais digitais: casos Itaú, O Boticário e Cacau-Show".

Em complemento ao tema do dossiê temos dois depoimentos de profissionais atuantes e antenados. Claudio G. Cardoso, João Abramo, Alexandre Martins e Elizabeth J. S. M. Freitas propõem aos leitores de Organicom o tema "Mídias sociais e risco de imagem", ressaltando a importância do monitoramento em tempo real dos temas relevantes para marcas e empresas discutidos nas diferentes ambiências midiáticas digitais. 0 depoimento de Mauro Segura, "A internet das coisas e a recriação do marketing", questiona o futuro que bate às portas de todos nós e do quanto estamos preparados para nos comunicar e relacionar com os dispositivos inteligentes decorrentes da internet das coisas. Um alerta mais que oportuno. 
A seção Espaço Aberto também teve seu conteúdo aproximado ao tema central desta edição. Os textos foram organizados a partir da discussão da visão de centralidade e transversalidade que o campo da comunicação hoje ocupa no tecido social contextualizado pela digitalização generalizada.

Visões de renovação do campo podem ser apreciadas nos textos de Victor Márcio Laus Reis Gomes - "Cultura, comunicação e estratégia na perspectiva sistêmico-discursiva"; e de Mônica Pieniz- "Tecnicidade como mediação estrutural no processo de trânsito das audiências: apontamentos para a comunicação organizacional contemporânea".

A comunicação pública, tão evidenciada e muitas vezes questionada em tempos digitalizados, é discutida por Antonio Teixeira de Barros e Cristiane Brum Bernardes - "Dilemas dos sistemas híbridos de comunicação institucional: análise das tensões e dos conflitos no projeto da Câmara dos Deputados"; Ângela Cristina Salgueiro Marques - "Comunicação pública e constituição de cenas de dissenso em contextos institucionais"; e Márcio Simeone Henriques e Lidiane Ferreira Sant'Ana - "A construção da proximidade na comunicação pública: mídia social e a ruptura da impessoalidade".

A práxis comunicativa emerge nos trabalhos de João Anzanello Carrascoza e Tânia Márcia Cezar Hoff- "Ditos e não-ditos: 0 Brasil e as práticas de consumo nos autoanúncios das agências de publicidade nos anos 1950"; Vasco Ribeiro- "Pragmatismo das fontes profissionais de informação: perspectiva teórica não-conspirativa da relação entre assessores de imprensa e jornalistas"; e Marcelo Kischinhevsky- "Rádios corporativas e customizadas: novos atores no mercado da radiodifusão sonora".

A edição no 22 de Organicom encerra com as tradicionais resenhas de obras recentes. Assim, apresentamos Caiu na rede. E agora? Gestão e gerenciamento de crise nas redes sociais, de Patrícia Brito Teixeira, resenhada por Anaíle Tarumi Moura, bastante focada no tema central de nosso dossiê, com o título "Lidando com crises na era das redes sociais difitais"; Marketing e comunicação de projetos socioculturais: experiências brasileiras e cubanas, de autoria de Mitsuru Higuchi Yanaze, Felipe Chibás Ortiz e Kleber Markus, docentes da ECA-USP, traz um conteúdo desconhecido para a maioria dos leitores - o mercado cubano, sendo instigante a resenha "Esperiências além das fronteiras culturais", de Maurício Mário Monteiro, como forma de conhecer o tema. Comunicação organizacional: dimensões epistemológicas e discursivas, organizado pelas professoras Ângela Cristina Salgueiro Marques e Ivone de Lourdes Oliveira, traz oportunamente o status contemporâneo do campo, tendo sido resenhado pelo professor Luiz Alberto de Farias com seu texto "Olhares em perspectiva sobre a comunicação organizacional". Por fim, Fernando Castro Adamefecha essa seção com a rica resenha "Una refrescante fuente de inspiración, humanismo y esperanza", sobre a obra Teoría de la comunicación productiva, de Abraham Nosnik Ostrowiak.

Como afirmamos desde o título desta apresentação, o número 22 de Organicom, por seu dossiê "Redes sociais: usos corporativos", chega aos leitores com um conteúdo robusto graças a todos os pesquisadores e profissionais que contribuíram com seus estudos e depoimentos para que ele viesse a público com um tema tão oportuno ao momento da comunicação nas organizações. Registramos um agradecimento especial ao Prof. Derrick de Kerckhove, que nos concedeu uma entrevista tipicamente do mundo digital - iniciou no face-a-face e terminou no ciberespaço! Por fim, um agradecimento à equipe editorial e aos pareceristas, pois sem eles esta edição não estaria disponível para todos.

Esperamos que os leitores tirem bom proveito desses textos e dessas pesquisas. 